\title{
FORESTCARE: Evaluating progress toward sustainable forest management in Alberta
}

\author{
by Andrew M. Carpenter ${ }^{1}$ and Winifred B. Kessler ${ }^{2}$
}

Forest certification programs establish standards for sustainable forest management (SFM), and processes for evaluating the practices of companies relative to those standards. FORESTCARE is a volunteer, provincial-level certification program initiated by the Alberta Forest Products Association, its members, and stakeholders. Using a participating woodlands operation in northern Alberta as a test case, we examined how SFM criteria are applied in the FORESTCARE program, and whether measurable progress is evident. We also compared the FORESTCARE audit process with corporate and government audits performed in the same year. The test case revealed specific, measurable changes in management that represent actual or potential progress toward SFM. However, the improvements could not be directly attributed to the FORESTCARE Program. Recommendations are provided for strengthening FORESTCARE processes and practices.

Key words: Alberta forestry, ecosystem management, FOREST$C A R E$, forest certification, forest planning, public participation, sustainable forest management
Les programmes de certification ont mis en place des normes d'aménagement forestier durable (AFD), et des processus pour évaluer les pratiques des compagnies qui doivent suivre ces normes. FORESTCARE est un programme de certification provincial non obligatoire mis en place par l'Alberta Forest Products Association, ses membres et les intervenants. À partir d'une opération forestière du nord de l'Alberta choisie pour constituer un banc d'essai, nous avons étudié comment les critères d'AFD s'appliquent au programme FORESTCARE, et si des progrès mesurables peuvent être enregistrés. Nous avons également comparé le processus de vérification de FORESTCARE avec les vérifications effectuées par l'entreprise et le gouvernement au cours de la même année. Le banc d'essai a révélé des changements spécifiques, mesurables dans l'aménagement et qui représentent un progrès actuel ou potentiel vers l'AFD. Toutefois, les améliorations ne pourraient être attribuées directement au programme FORESTCARE. Des recommandations sont présentées pour renforcer les processus et les pratiques contenues dans FORESTCARE.

Mots-clés: foresterie en Alberta, aménagement des écosystèmes, FORESTCARE, certification forestière, planification forestière, participation publique, aménagement forestier durable

\section{Introduction}

Foresters and natural resource planners are facing significant changes in many aspects of their work, including unprecedented demand for stewardship and accountability. The pressures for change have reached the marketplace, with implementation of certification schemes that allow consumers to differentiate among companies on the basis of their practices and records of resource stewardship. All such programs establish standards for sustainable forest management (SFM), and processes for evaluating the practices of companies relative to those standards. There are two basic approaches: product certification, and systems certification.

Product certification evaluates the origins of the product with respect to ecological, social and economic performance indicators for SFM. An audit is performed to assess compliance, and those who pass generally earn the right to use a product certification stamp and to advertise that the product originated from a sustainably managed forest (SAF Study Group 1995). System certification assesses whether a company has processes in place to achieve SFM objectives and goals in a consistent manner that promotes continuous improvement. A systems audit usually evaluates planning, quality control measures, record keeping, regulatory compliance, employee training and education, and staff requirements. It is generally less prescriptive

\footnotetext{
${ }^{1}$ University of Northern British Columbia, 3333 University Way, Prince George, BC V2N 4Z9. Current address: 1016 11th Avenue SE, Slave Lake, AB TOG 2A3. ${ }^{2}$ University of Northern British Columbia, 3333 University Way, Prince George, BC V2N 4Z9. Author to whom correspondence should be sent.
}

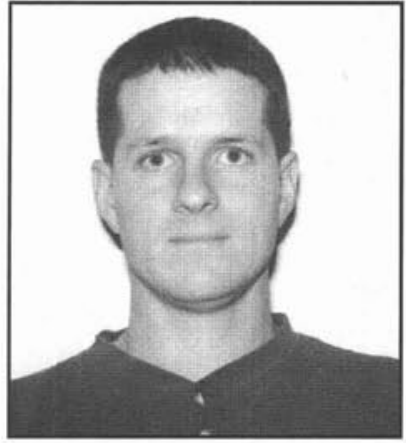

Andrew Carpenter

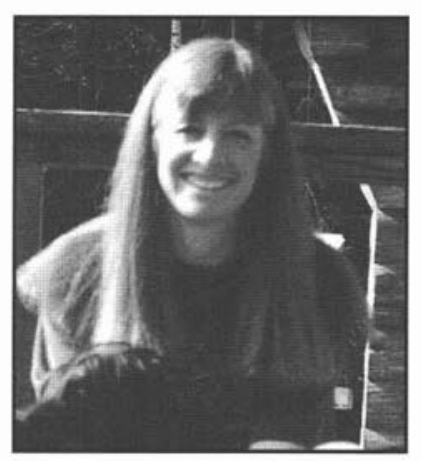

Winifred Kessler and more goal oriented than product certification (SAF Study Group 1995).

In both kinds of certification, voluntary participants must demonstrate a willingness to be audited by an independent third party (Armson 1996, Hughes 1996). The audit is intended to establish credibility by ensuring that certification standards are being met, and by providing for public participation in the process.

The three main parties in forest certification - the public, industry and government - differ in their interests, roles, and perspectives. The public's main interest is to help achieve, through exercise of consumer choice, greater accountability in forest practices (Armson 1996, ARPFA 1996). Corporations invest in certification schemes on the assumption that consumers will search out and pay for products that are certified, thereby rendering a competitive advantage to those companies (Bombay 
1996). Within the forest industry generally, there is awareness of public interest in forest sustainability and a desire to improve consumer acceptance and confidence (SAF Study Group 1995). Although some corporations are sceptical of the assumption that certification will bring competitive advantage (Berg and Olszewski 1995), early indications are that consumers are willing to pay more for certified wood products (SAF Study Group 1995). Retailers and wholesalers suggest there is room for growth in this marketing niche because the demand for certified products is not being fully met (Mater 1995).

Governments differ significantly in their approaches for improving accountability and promoting the objectives of SFM. British Columbia chose a strongly regulatory approach with the enactment, in 1995, of the BC Forest Practices Code. The Code featured highly prescriptive regulations and stiff enforcement penalties to promote progress toward SFM. Other governments eschew regulation of the forest industry; voluntary certification is seen as an alternative means to improve performance. In Alberta, for example, industry took the lead in promoting SFM through FORESTCARE, a voluntary certification program.

\section{SFM Themes and Principles}

If the purpose is to measure consistency with SFM, any certification scheme must have an operational definition or set of principles on which to base its evaluations. SFM has been widely criticized by policy makers and foresters as an imprecise or "fuzzy" concept (More 1996, Gilmore 1997). Different organizations that profess to practice SFM may create different interpretations and expectations, according to their own policies and goals. More (1996) suggested that a consistent definition will help natural resource managers narrow the gap between concept and application, limit the range of corporate interpretations, and promote a consistent level of implementation.

The difficulty is that ecosystems - including the human component - are exceedingly complex and variable. Hence, there is no single vision for what SFM plans should strive to achieve, and how such plans should be implemented (Kessler 1998). That variability is, in itself, a fundamental idea in the SFM concept: every location on Earth has a different combination of ecological, economic, cultural, and political conditions. Thus, every forested landscape provides a unique context for people to develop SFM approaches. There is no cookbook for SFM planning and management, nor will there ever be one.

Given this complexity, it is unlikely that SFM will ever be captured in a simple, crisp definition. The Ecological Society of America, having thoroughly evaluated the scientific basis for "ecosystem management" (the American term for SFM), offered this broad (some might say "fuzzy") definition: "management driven by explicit goals, executed by policies, protocols, and practices, and made adaptable by monitoring and research based on our best understanding of the ecological interactions and processes necessary to sustain ecosystem composition, structure, and function" (Christensen et al.1996). Although a unified definition remains elusive, there is widespread agreement that SFM represents a true "paradigm shift" from traditional sustained-yield forestry. As well, there is consensus about the basic principles (Kessler et al. 1992, Bengston 1994, Grumbine 1994, Rowe 1994, Galindo-Leal and Bunnell 1995, Knight and Bates 1995, Christensen et al. 1996, Mangel et al.1996). These principles are described in the following sections.

\section{Ecosystem Integrity}

Traditional sustained-yield management aims at sustaining the flows of specific products (i.e., wood fibre) to meet human needs, within constraints imposed to minimize adverse effects to other resource values and the environment. SFM expands this mandate to include a diverse array of ecological services, environmental health objectives, and social and economic values. SFM strives to maintain ecosystem integrity, including native biological diversity and the ecological patterns and processes that underlie diversity and long-term productivity.

\section{Disturbance Ecology}

In traditional approaches, manipulations of the forest were usually carried out to maximize product yields and/or the efficiency of operations. SFM recognizes forests as dynamic systems that are shaped and sustained through time by patterns of natural disturbance. It assumes that biodiversity conservation and other objectives can best be achieved by designing treatments and disturbance patterns that "work with nature" (rather than fight against nature) by mimicking natural disturbance regimes.

\section{Hierarchical Scales}

The focus of traditional management was at the level of forest stands, with little attention to spatial relationships at larger scales. SFM recognizes that the conservation of biological diversity, maintenance of watershed health and landscape aesthetics, consideration of species with large home ranges, and many other objectives require consideration of patterns and relationships at multiple spatial scales, and of the linkages between scales. Similarly, the relevant time frames in SFM include very long horizons (centuries and multiple rotations) as well as the short-term planning that prevailed in traditional forest management. SFM recognizes the need to understand the long-term and cumulative effects of management, such that decisions today will not foreclose options for future generations.

\section{Uncertainty}

Three sources of uncertainty are of concern in natural resources management: 1) our poor understanding of how ecological systems work, including the basic processes that underlie their dynamics and sustainability; 2) inaccuracies in our measurements, inventories, models, and assumptions; and 3) the inherent chaos found in nature, such that there will always be chance events and situations that are unpredictable. The magnitude of uncertainty in ecological systems means that we do not understand the potential effects and consequences of our management actions nearly so well as was previously assumed. Two principles of SFM address the uncertainty problem. The precautionary principle mandates a conservative management approach in the face of poor information or uncertain events. The principle of adaptive management mandates adoption of "a systematic approach to improving management and accommodating change, by learning from the outcome of management interventions" (Taylor et al.1997). The fundamental idea is to replace trial and error with a structured approach to learning.

\section{Social Issues, Including Equity}

SFM recognizes the inter-dependence of people and ecosystems. Humans have profound effects on ecological process- 
es, and in turn are affected by them. People benefit from the cultural and spiritual values of forests as well as the economic values. Humans and their activities must be treated as integral components of forest planning and management, rather than as "externalities" in the traditional model. SFM assumes inter-generational sustainability as a precondition for management rather than as an afterthought. This is an obligation to manage forests today in a manner that does not compromise the needs and options of future generations (World Commission on Environment and Development 1987).

\section{Public Participation and Accountability}

In the traditional approach, forest planning and decision making were the domain of specialists and administrators. SFM recognizes the need for meaningful participation by all people who have an interest in - or stand to be affected by - the outcomes of management. Planning to support SFM must be a "transparent" process that requires and benefits from an informed and involved public. Open and honest communications, and a willingness to be held accountable, improves trust between forest managers and communities and offers industry an opportunity to demonstrate responsibility.

\section{Major Certification Schemes}

Certification schemes exist at the international, national and provincial levels.

\section{International Level}

The International Standards Organization (ISO), which includes more than 100 member nations, has developed certification achievement standards for the past 50 years (Armson 1996). The ISO mission is to standardize the goods and services traded in international commerce. Following the United Nations Conference on Environment and Development (UNCED) in 1992, the ISO initiated development of a new series I. of standards that would measure a company's performance with respect to environmental management tools and systems (Kiekens 1998). The series includes standards relating to environmental management systems, environmental auditing, environmental labelling, environmental performance evaluation, life-cycle assessment, and terms and definitions. More recently the ISO undertook development of guidelines and audit procedures for SFM (Cabarle et al. 1995).

Another important international program is the Forest Stewardship Council (FSC), headquartered in Oaxaca, Mexico. The FSC was established in 1993 to promote environmentally appropriate, socially beneficial, and economically viable management of the world's forests by establishing a set of globally recognized principles and guidelines for SFM certifiers (Cabarle et al. 1995). Although the FSC principles and criteria apply to all tropical, temperate, and boreal forests, the system does not require total compliance in all cases. Major failure in one or more principles will normally disqualify a participant or lead to decertification. The principles apply to diverse facets of forest management, including compliance with laws and treaties, tenure rights and responsibilities, rights of indigenous peoples, community relations and workers' rights, diversity of forest benefits, environmental impacts, management planning processes, monitoring and assessment, maintenance of natural forests, and management of plantations (Cabarle et al. 1995).

\section{National Level}

An important national program is the Canadian Standards Association (CSA) - a not-for-profit, independent standards-writing organization. The CSA was approached by the forest industry to develop a system of forest management certification that would satisfy the range of social, cultural, and environmental concerns in Canada (Armson 1996). In 1994, the CSA initiated a SFM project modelled after the ISO environmental management systems approach (Lapointe 1998). The CSA standards are intended to be national in scope while allowing for regional variation in economic, social, and ecological conditions. Following a successful initial audit, participants in the CSA system must submit to a full audit within three years, with subsequent audits at five-year intervals (Armson 1996). An annual report, including all audit results, must be made available to the public.

\section{Provincial Level}

The FORESTCARE program is a provincial-level initiative of the Alberta Forest Products Association (AFPA), its members, and stakeholders. The AFPA consists of 67 member companies involved in the manufacture of lumber, pulp and paper, and secondary manufactured products. Together, they account for about 95\% of Alberta's annual allowable cut (FORESTCARE 1996). FORESTCARE was initiated in 1990 and implemented in 1993 as a non-regulatory alternative for demonstrating compliance with SFM principles and practices.

How well is FORESTCARE working to encourage SFM among participating companies in Alberta? The remainder of this paper reports our qualitative evaluation of the program with respect to the principles and objectives of SFM. We begin by describing the basic approach and features of FOREST$C A R E$, and examine its application to a participating woodlands operation in northern Alberta. We then critically examine the program against principles and criteria of SFM. Finally, we compare the FORESTCARE audit process with corporate and government audits conducted on the woodlands operation in the same year. Our purpose is to evaluate whether the FORESTCARE program is changing forest management in Alberta in specific, measurable ways that represent actual or potential progress toward SFM.

\section{FORESTCARE Principles and Features}

An initial step in the FORESTCARE program was to develop a Code of Forest Practice. This document includes FORESTCARE's statement of philosophy:

\begin{abstract}
Alberta's forests have environmental, economic and social values. FORESTCARE has been created by Alberta's forest products industry to help protect these values while sustaining the health of the forest. FORESTCARE is an ethic on which we conduct our business. It reflects a pledge by our member companies to lead progressive operations and continuously improve our performance in light of new knowledge and abilities. (FORESTCARE 1997a)
\end{abstract}

The program aims to promote a healthy and sustainable forest industry while protecting the forest, the environment, and the community. Supported by Guiding Principles and Codes of Practice, it guides decision making and operations in accordance with corporate performance standards. 
According to the AFPA, the FORESTCARE program was not a consumer-driven initiative; rather, it was designed by industry to build government and public confidence in the forestry sector (FORESTCARE 1997b). The program was intended to complement existing regulatory requirements through voluntary corporate initiative and related activities, such as research. FORESTCARE was aimed at self improvement of individual companies and overall improvement of industry's image and outlook. All AFPA members were encouraged to participate in the program, although participation did not guarantee certification status (FORESTCARE 1996).

FORESTCARE rejected the notion that there is one "right" way for a company to meet the intent of a code. Companies differ in their management styles depending upon local circumstances, type of operation, product lines, and community interests (FORESTCARE 1996). The essential elements of FORESTCARE's approach to SFM were established in its Guiding Principles and Codes of Practice, upon which performance expectations were established.

The Guiding Principles require a commitment by participating members to practice sustained yield harvesting, manage for multiple-use objectives, protect the environment, protect employee and public safety, provide meaningful opportunities for public participation, and contribute towards ensuring future resource sustainability (FORESTCARE 1997a). The Codes of Practice deal with three major facets of the Alberta forest industry: the forest, the environment, and the community. Contained within these codes are more specific management goals related to land-use, forest management planning, harvesting, reforestation, forest protection, operations, processes and equipment, waste control, safety, communication and sustainable development (FORESTCARE 1997a).

Corporate participants in the FORESTCARE certification program must be members of the AFPA and agree to:

- conduct operations according to FORESTCARE codes;

- designate a FORESTCARE coordinator;

- perform annual self-audits and submit action plans for improvement as well as a schedule for completion; and

- commit to and designate a date for a formal FORESTCARE audit to be carried out within three years of committing to membership.

Performance is evaluated through annual self-assessments and a full scale audit every three years. The audit process is based on 72 Codes of Practice and 119 standards of performance and is administered through 360 benchmark questions. Audited companies are assigned performance scores for the individual FORESTCARE criteria, and a total score is determined. The performance levels are defined as follows (FORESTCARE 1996):

- Alberta State of the Art-performance that is exemplary in Alberta (requires a score $\geq 95 \%$ ).

- FORESTCARE - meets or exceeds the industry's elevated standard (requires a score $\geq 75 \%$ ).

- Currently Accepted Practice - meets or exceeds industry's minimum standard (requires a score $\geq 50 \%$ ).

- Unsatisfactory - performance below the industry's standard for acceptable practice.

No company qualifies for certification unless it achieves an overall performance level of "FORESTCARE" $(\geq 75 \%$ on its audit). Re-certification audits are performed every three years after initial certification to ensure continuing compliance and improvement.

Certain requirements were instituted to ensure the credibility of the audit process (FORESTCARE 1996): only qualified auditors can perform audits; the auditing process is closely scrutinized by the AFPA and independent auditors; FORESTCARE auditors are experienced representatives of AFPA member companies, or qualified independent consultants who understand the issues and program objectives and have the auditing skills required for the program; auditors must have at least five years of relevant woodlands experience, complete an auditor workshop provided by the AFPA, and pass an exam; and local community leaders are involved as independent observers.

\section{A Woodlands Case}

We examined a case in detail to better understand how SFM criteria are applied in the FORESTCARE program, and to search for evidence of measurable progress toward SFM. Our case is a participating woodlands operation in northern Alberta. We do not identify the company or operation so as to protect the confidentiality of the participant.

This case focussed on a medium-sized forest products manufacturing facility with an annual allowable cut of about $284000 \mathrm{~m}^{3} / \mathrm{yr}$. Forest tenure agreements that negotiate timber rights between forest companies and the Alberta government are either land-based (Forest Management Agreement) or volume-based (Timber Quota). The operation in our example relied on a fibre supply granted under the government regulated, volume-based quota system. Henceforth, we will refer to our case operation as the "Quota Holder."

\section{Information Sources}

We used several information sources to obtain a comprehensive picture of the Quota Holder's past and present operations. Interviews were conducted with the Director of the FOREST$C A R E$ program and with registered professional foresters who were involved in the program both as corporate participants (employees of the Quota Holder) and as auditors (consulting foresters). Additional information was obtained through correspondence with corporate FORESTCARE coordinators and with staff and managers of the Alberta Land and Forest Service.

More detailed information was obtained in a visit to the woodlands operation of the Quota Holder, who provided access to General Development Plans (GDP), Annual Operating Plans (AOP), and other relevant documents produced before and after the company's enrollment in the FORESTCARE program. Attendance at stakeholder meetings in August 1997 and January 1998 provided additional perspectives and details relating to the Quota Holder's operations.

The Quota Holder made available the results of an audit performed by the Alberta Land and Forest Service in summer 1997 to assess compliance with provincial regulations and operational ground rules. An internal corporate audit completed in fall 1997 provided additional information about management performance. We also examined documentation of the Quota Holder's FORESTCARE performance audit, which is available for public review. The Quota Holder had earned ratings at the Alberta State of the Art, FORESTCARE, and Currently Accepted Practice levels for the various performance criteria.

Information was also sought in current publications, annual reports, audit protocols, and report cards available from the 
AFPA and FORESTCARE participants. These sources provided additional details on the program's philosophy, certification criteria, auditor training requirements, and overall performance ratings of certified members.

\section{Evaluation Criteria}

Evaluation of the Quota Holder's woodland operation required specific conditions or processes (i.e., criteria) by which we could identify actual or potential progress toward SFM. We used the basic principles of SFM (described above) as our starting point, and developed the following evaluation criteria for each category.

\section{Ecosystem integrity}

Does the available information indicate that the Quota Holder is attempting to manage for biodiversity by considering a wide range of biological life forms within the forest? Are there objectives for maintaining key ecological attributes within their natural ranges of variability? Do forest harvest operations work toward minimizing detrimental site disturbance? Does the Quota Holder attempt to differentiate ecosystem and site differences, and manage for them accordingly? Are ecological indicators in place to assess and monitor management performance?

\section{Disturbance ecology}

How are natural disturbance agents and processes considered in planning? Are relationships of disturbance to ecological patterns and processes discussed? Are management decisions and actions being evaluated with respect to landscape dynamics and interactions with natural processes? Is there an attempt to design management treatments so as to emulate natural processes or landscape patterns? Is a general feeling of "working with nature" evident in this woodlands operation?

\section{Hierarchical scales}

Does the Quota Holder address ecological issues in the context of multiple and appropriate scales? What spatial scales are included in planning and analysis? What is the time horizon for planning? Is consideration given to the multiple and cumulative effects of management? Are these effects addressed in terms of management objectives and mitigative measures?

\section{Uncertainty}

Does the Quota Holder indicate an intention to improve ecological knowledge and understanding? Is the management team proactive in addressing management uncertainties and contingencies? Is the precautionary principle in evidence? To what extent is the Quota Holder moving toward an adaptive management approach?

\section{Social issues}

Does the Quota Holder express an obligation or intention to maintain the forest's productivity for future generations? Is there concern for maintaining a full range of future management options? Does management address a full range of forest values and uses, including social values? Does the economic health of local communities appear to be of concern? Are measures in place to promote forest product diversification and value-added enterprises? Are production expectations consistent with public concerns about regional and local economic stability?

\section{Public participation and accountability}

Is the public actively involved in planning and decision making processes? How is management attempting to understand and address people's concerns? Does management openly and accurately communicate the rationale for its decisions and actions? Are public processes open and honest? Are management plans responsive and flexible? Do managers seem to be accountable to the public?

\section{Evaluation Results}

Using all information sources combined, we considered the degree to which the Quota Holder's woodland operation was consistent with our evaluation criteria. In particular, we looked for differences before and after the Quota Holder's enrollment in FORESTCARE, which might reasonably be interpreted as change in response to the program. In the following sections, we report our observations for each SFM principle.

\section{Ecosystem integrity}

Comparing the General Development Plan (GDP) for 1989-93 with that for 1997-2002 provided evidence of significant change in harvest unit design so as to accommodate biodiversity objectives. The newer GDP includes numerous concerns and management provisions not addressed in the earlier plan. For example, the newer plan contains provisions to group harvesting units of various sizes to minimize access development and to simulate natural disturbance patterns. Road deactivation strategies are clear and are scheduled to accommodate wildlife management concerns, such as disturbance during vulnerable seasons. Harvest unit design features include feathering along cut-block edges to promote wind-firmness. Retention patches containing merchantable and non-merchantable trees will be retained within cut-blocks larger than 5 ha to maintain wildlife habitat and limit the line of sight. Patches will vary in size from small clumps (six to eight trees) to patches of 5-10 ha, and will be irregularly distributed throughout each cut-block.

Alternative harvesting practices will be implemented in sensitive areas to minimize impacts. Examples include conventional systems, single tree selection, horse logging, and helicopter logging. Log sorting by length and diameter will occur in the forest to minimize fibre loss at the mill.

Riparian buffers will be established to protect watershed and other ecological values. Preliminary reconnaissance of every harvest area will be performed to facilitate proper field layout and harvest operations. Watercourses within each block will be identified and traversed by global positioning systems (GPS), and proper watercourse crossings established prior to commencing harvesting operations. Proposed future development in the Quota Holder's management area will address fishery concerns through stakeholder meetings and mitigative measures.

Longer-term management into the next rotation will follow mixed-wood management goals and objectives, utilize mixedwood yield curves, and discard severely degrading site preparation equipment (e.g., ripper plow). Forest stands will be managed to attain species, structural and age class diversity objectives.

Ecosystem classification, including stratification of harvest units, is extensively used in the 1997-2002 GDP for planning harvesting, reforestation and other management activities. Provisions to modify harvesting and site preparation practices, man- 
age ecosystems on a landscape level, and actively participate in ecological research all suggest progress toward the ecological principles and practices of SFM.

Overall, we found that most - but not all — of the changes between the old and new GDPs were consistent with ecological principles of SFM. It remains unclear how the Quota Holder intends to retain soil nutrient capitals by continuing the practice of whole tree harvesting.

\section{Scale Issues and disturbance ecology}

In the past 10 years, the Quota Holder's approach has changed with respect to spatial scales of consideration, layout patterns, and consideration of habitat needs and relationships. In the 1989-90 Annual Operating Plan (AOP), harvest blocks were designed under a two-pass system whereby half the volume was removed in the first pass and the rest left for harvesting at a later date. Typically, the blocks followed a "checker-board" pattern — a decidedly non-ecological approach. Provisions to mitigate ecological impacts, while meeting government requirements, were minimal - for example, cutting schedules might be adjusted within a watershed where sensitive wildlife was known to exist. Government's general requirements, such as retention of unmerchantable patches of vegetation to act as wildlife tree patches, were provided for in the plan. However, the plan lacked specific information about wildlife species and habitat areas, and did not specify strategies or actions to prevent or mitigate potential impacts.

Examining more recent plans, we found greater consistency with SFM considerations of ecological process and scale. In the 1997-98 AOP, for example, the checker-board pattern for cut blocks is replaced by a landscape design approach that addresses ecological objectives. The plan includes measures to reduce access-related impacts to wildlife by concentrating intensive harvesting operations in specific areas. The plan includes strategies for important species. For example, a caribou management strategy developed with stakeholders calls for the grouping of harvesting units to minimize access development, and a commitment to daily ground and aerial searches for caribou. In the event that caribou and/or caribou tracks are observed, all harvesting operations within the identified blocks will cease. The strategy includes the closure of the affected blocks immediately following the completion of operations, and provisions to monitor caribou populations through stakeholder and consultant activities.

The Quota Holder is investigating the cumulative impacts of its management strategies through the following projects: water quality studies and monitoring; forest cover re-inventory, and the EMEND (Ecosystem Management Emulating Natural Disturbance) research project based at the University of Alberta. In current plans, management goals are comprehensive in scope and strategies are more specific than before.

\section{Uncertainty}

According to members of the Public Advisory Committee, the Quota Holder seems committed to using the best information and technology available while acknowledging significant knowledge limitations with respect to SFM. Management personnel agree that a pro-active team approach, scientific knowledge, and adaptive management strategies are essential for success.

Involvement in the EMEND project offers opportunity to strengthen the knowledge base and implement an adaptive man- agement approach (Spence et al. 1999). The project is a joint venture between the Quota Holder, other forestry corporate interests, the University of Alberta, the University of Calgary, the Forest Engineering Research Institute of Canada, and the Sustainable Forest Management Network (a national research program). Focussing on the study of ecosystem dynamics and responses to management intervention, the investigators are striving to identify the most important attributes to manage, measure and monitor. EMEND activities include extensive baseline data collected prior to harvest, and post-treatment monitoring to assess changes in plant community types, growth and yield, light, natural regeneration patterns, wildlife habitat relationships, and changes in below-ground processes. Strengths of the project include the cooperation between companies having overlapping tenure rights, and the degree of collaboration between scientists and managers in diverse disciplines - all essential requirements for adaptive management (Lee 1993).

\section{Social issues}

Forest management in the Quota Holder's area is guided by five-year GDPs and one-year AOPs. Our examination of plans that existed prior to FORESTCARE involvement yielded the following observations. The focus was clearly on timber production, with the lion's share of time and resources going to timber appraisals and harvest planning. Mention of other resource values - and provisions to mitigate impacts to watersheds, scenic vistas, recreation, and livelihoods such as trapping and hunting - were scarce. An intention to minimize impacts was stated, but no strategies and very few actions were specified. Forest protection was limited to fire management, pest control, and other threats to timber production. Nothing specific was in place to address social concerns that might arise with the harvesting of watersheds.

The more recent plans reveal a growing responsiveness to social values and sensitivities. For example, local concern about visual quality surfaced when harvesting units were planned close to a popular ski area. This concern was discussed in a series of public meetings, and digital terrain models were used to explore alternative cut-block designs. Although the harvest plan for the area was already in place, public input was used to modify the planned activities and achieve consensus among the affected parties.

Neither the provincial forestry regulations nor the FOREST$C A R E$ program require the Quota Holder to operate under an integrated resource plan (IRP) that provides for a full range of resource values and objectives. However, the Quota Holder opted to develop an IRP in collaboration with its Public Advisory Committee, and has committed to implementation of the plan. In this way, a more diverse set of values and concerns will be integrated into future management of the Quota Holder's area.

\section{Public participation}

Our evaluation revealed that during the past 10 years, the Quota Holder has become increasingly open to public input and compromise. Through the Public Advisory Committee, staff interact with interested citizens and jointly develop social, economic, and environmental objectives for the area. The Committee includes representatives from environmental groups, the schools, municipal and provincial government, industry, First Nations, and others to achieve a breadth of perspective. 
Also evident is a willingness to take stakeholder concerns seriously. For example, public concern about site degradation associated with site preparation (in particular, from ripper plow treatments) resulted in the design and implementation of new technology (the dual path mounder) to minimize those impacts. Other examples include protection of First Nations burial sites, trappers' cabins, and other culturally significant resources. A move to alternative harvesting practices is also in evidence in response to public concerns and preferences.

The processes for public involvement have evolved from simple notification (e.g., letters advising stakeholders of upcoming activities), to "open houses" and other information sessions, to full participation in planning. Most importantly, the Quota Holder now strives to elicit and address public concerns and suggestions in the beginning, and to maintain accountability in all stages of the planning process. Plans are submitted to stakeholders for review and discussion. If stakeholders do not approve of the Quota Holder's management strategies, the plan is revised to achieve group consensus. After approval by the stakeholder group, the plan is submitted for Lands and Forests Service approval and the Quota Holder becomes accountable to the public for the plan's implementation.

Overall, our observations suggested that public involvement is taken very seriously by management and is not a peripheral element or afterthought in the planning process.

\section{Comparing Audit Processes}

To gain a comparative perspective on the FORESTCARE approach, we reviewed three different audit processes conducted on the Quota Holder in 1997 to evaluate relative strengths and weaknesses.

\section{FORESTCARE Audit}

A FORESTCARE woodlands audit was performed on the Quota Holder's operations in summer 1997. Our review of the preliminary report revealed an overall rating at the level of FORESTCARE. This level of achievement certifies that the Quota Holder meets or exceeds the industry's elevated standard of an overall score greater than $75 \%$. The audit result was validated by certified auditors and published in an external observer's report. Our observations about strengths and weaknesses of the FORESTCARE woodlands audit process include the following.

\section{Information sharing}

The FORESTCARE approach actively promotes corporate information sharing. It provides opportunity for companies to share management approaches and policies, and to learn from one another's experience. On the other hand, the audit process lacks measures to verify that new information is integrated into the management systems of audited companies (e.g., requirements for the timely updating of resource databases).

\section{Advance audit notification}

Companies preparing for a FORESTCARE woods audit are given two week's notice of the specific cut-blocks that will be field checked during the site visit. This "advance warning" may call the credibility of the field visit into question.

\section{Process objectivity}

Subjectivity may enter FORESTCARE audits in the way that a company selects and presents the evidence of its performance.
There is potential for inconsistency in auditor perspective about the type of evidence required, and what constitutes acceptable benchmark attainment. Company personnel are allowed to discuss benchmark achievement and scores with auditors. Although some level of dialogue between auditors and corporate representatives may help correct audit oversights, there exists potential for abuse of the "negotiation" privilege.

\section{Auditor competency}

FORESTCARE woods auditors must have appropriate training, satisfactory field experience, and a commitment to the program. Their qualifications and work are monitored by AFPA representatives. These requirements help ensure that approved auditors are qualified to conduct objective and critical assessments of company performance relative to the FORESTCARE criteria.

\section{Scoring}

The score ranges for rating performance are broad. For example, the Quota Holder's score of $93 \%$ was only $2 \%$ below the level required for Alberta State of the Art. Should the Quota Holder be considered equivalent to a company that barely scores the $75 \%$ required for certification at the FORESTCARE level? Such broad ranges may obscure significant differences in performance.

\section{Post-audit accountability}

The AFPA system does not require that corporations submit action plans for improvement. Companies audited by the FORESTCARE program are accountable to themselves to use the information provided. Certification remains effective for three years, regardless of what improvements or lapses may occur in the interim. No mechanisms are in place to revoke corporate certification for non-compliance with the protocol for SFM.

\section{Performance feedback}

Audited companies are given a copy of their rating for each audited criterion and a follow-up questionnaire to be returned to the AFPA. However, the AFPA does not provide a detailed report to highlight successes and deficiencies noted by the auditors during the audit process. Such would provide important feedback to companies for continually improving their performance.

\section{Government of Alberta Audit}

An audit team comprised of personnel of the Alberta Lands and Forest Service (LFS) performed an audit on the Quota Holder's woodlands operations in the summer of 1997 to determine compliance with provincial forestry regulations and operating ground rules. The Quota Holder passed the audit, having met all Government of Alberta regulatory requirements. It emerged as one of the top performers in its category, and LFS personnel commended the Quota Holder for certain aspects of its practices. Examples included seedling performance in plantations, erosion control within harvesting units, more than adequate watercourse classification and buffers, and an exemplary job of industrial waste management. Minor regulatory deviations were also noted to allow the Quota Holder to make necessary improvements.

Our review of the LFS audit process produced the following observations about its strengths and weaknesses. 


\section{Information sharing}

The government audit process did not include provisions to encourage inter-corporation sharing of experiences and information.

\section{Advance audit notification}

Corporations preparing for LFS audits are notified three months in advance of the site visit. However, no prior notification is given of the specific cut-blocks to be field checked.

\section{Process objectivity}

The provincial forestry regulations are used as the requirements and standards for the audit. These tend to be prescriptive, allowing little room for interpretation by the auditors. Limited communication is permitted between LFS auditors and company staff.

\section{Auditor competency}

Qualifications for LFS auditors include more than five years experience in forest operations, and completion of a certified auditor training course. A team leader must have more than 10 years experience in operational forestry. Credentials as a Registered Professional Forester (RPF) are not required, although an RPF may be assigned to oversee the process.

\section{Scoring}

A pass or fail system is used. The audit simply determines whether the company meets the provincial regulations for woodlands operations, and does not evaluate performance relative to principles and standards of SFM.

\section{Performance Feedback}

Results are provided as written comments to the audited unit. Fines and/or letters of reprimand are issued for non-compliance with provincial regulations.

\section{Corporate Audit}

The parent company performed an audit of the Quota Holder's woodlands operations in the fall of 1997. Personnel from other forestry divisions within the company participated in an assessment of the Quota Holder's progress toward achieving corporate management goals and objectives. The audit included the various systems relating to the company's forest practices compliance management policy, including: standard operating procedures; supervision; internal communication; document management; equipment acquisition, deployment and utilization; maintenance programs; knowledge of industry practices; and, incidence reporting. Our review of the corporate auditing revealed the following strengths and weaknesses.

\section{Information sharing}

Corporate auditing promotes the sharing of information and experiences within the company and among other companies, thus accelerating learning within the industry as a whole.

\section{Advance audit notification}

Companies that are preparing for corporate audits are notified in advance of the site visit; however, no prior information ("advance warning") is supplied to indicate the specific areas that will be visited until the audit commences.

\section{Process objectivity}

As with the FORESTCARE audit, corporate audits appear susceptible to some subjectivity that reflects the opinions and management style of the auditors and the regulatory environment to which they are accustomed. Unlike in the FORESTCARE process, however, staff involved in a corporate audit have limited communication with auditors, and debate is discouraged.

\section{Auditor Competency}

Corporate audits are performed by experienced corporate staff and Registered Professional Foresters. In the case we examined, company personnel were carefully selected to ensure a thorough and credible review.

\section{Scoring}

The quota holder received a score of $87.5 \%$ for forestry policy implementation, and $91.7 \%$ for the environmental criterion. These scores represented a significant improvement over the previous corporate audit, indicating that the Quota Holder's management team made necessary adjustments and measurable improvements in their operations to satisfy corporate expectations.

\section{Performance feedback}

Details of the corporate audit were submitted in writing to the Quota Holder woodlands team. Woodlands personnel were then required to submit action plans to address shortfalls and remedy deficiencies. In the corporate audit process, staff are held accountable to upper management for making the needed corrections.

\section{Conclusions and Recommendations}

Forest certification is not an end in itself; rather, it is a means for industry and the forestry profession to express their commitment to the principles and goals of SFM, and to demonstrate performance in ways that are meaningful to the public. To be effective, certification schemes (and especially their audit processes) must be accepted as credible, effective, and informative.

We conclude that the Quota Holder's management is changing in specific, measurable ways that represent actual or potential progress toward SFM. Our examinations of the Quota Holder's development and operational plans for past and current periods revealed increases in the consideration of SFM principles and objectives. The newer documents address ecological integrity and processes, wildlife habitat relationships, soil and water protection, and cumulative effects at a level of specificity lacking in the earlier plans. The purview of management has been broadened to include cultural values and social preferences. The Quota Holder's participation in the EMEND project indicates a commitment to research, innovative approaches, and an adaptive approach to management. The formation and activities of the Public Advisory Committee provide tangible evidence of progress in public participation. The Quota Holder significantly exceeds the level of performance represented in Alberta government regulations, and appears to be embracing concepts and practices of SFM.

However, our evaluations do not allow us to credit the FORESTCARE program with these improvements. For the case examined, we suggest that the impetus for progress is stronger within the company (e.g., corporate policies, committed per- 
sonnel) than that imposed by the AFPA initiative. We found that the FORESTCARE audit and follow-up processes were less rigorous than those of the corporate audit performed by the Quota Holder's parent company. In the corporate process, unlike the FORESTCARE approach, no advance notice was given of the specific sites to be field checked. Moreover, the "give and take" discussions between auditors and unit personnel during the FORESTCARE process were more restricted in the corporate audit. As well, the corporate process had superior feedback mechanisms, and the audited unit was held accountable to implement a plan of action to improve performance. Compared to the FORESTCARE and corporate processes, the government audit was the least rigorous, and lacked incentives and mechanisms to stimulate improvement.

We suggest that the need for credible and effective certification schemes is increasing as governments reduce field staff and activities in response to tightening budgets. In Alberta, for example, recent decreases in provincial forest personnel necessitated the replacement of frequent and regular field inspections with infrequent audits. Reliable audits through the FORESTCARE program will be critical if the Alberta forest industry is to succeed in building public and government confidence in industry stewardship. If credibility and public confidence are the primary aims of certification, then the FOREST$C A R E$ approach has room for improvement. We offer the following recommendations for strengthening FORESTCARE processes and practices:

- During audits, participation by company personnel should be limited. Currently, there is too much opportunity for dialogue and debate between auditors and company representatives.

Companies should not be notified in advance of the specific sites to be visited by the auditing team.

The costs and benefits of performing re-certification audits every two years (rather than three years) should be evaluated.

- The scoring ranges (for determining certification status) should be tightened or refined to provide a more sensitive indicator of change in performance.

- Stronger feedback mechanisms are needed. Detailed written comments and suggestions for improvement should be returned to the audited company in a timely manner.

- Companies should be encouraged or required to develop action plans (including time lines) in response to audit results, and to initiate monitoring to ensure implementation and accountability.

- An option to revoke the certification status of non-compliant members should be exercised. This would require "spot checks" or other procedures between audits.

- Create and authorize an Ethics Board to promote corporate accountability and adjudicate disputes that arise in the auditing process.

- Establish a "hot line" to provide information and receive complaints from the public.

\section{Acknowledgements}

We wish to thank the following people for their contributions of information, time, or encouragement: Deborah Carpenter, Don Carr, Dan Gilmore, Joerg Goetsch, Dennis Keyte, Jeff Reynolds, Len Rimmer, William Rugg (FORESTCARE), and Tim Vinge. We extend special thanks to Dean Caron for his invaluable assistance throughout. Publication support was provided by the Sustainable Forest Management Network.

\section{References}

Armson, K.A. 1996. Forest certification and Canadian forestry an overview and update. For. Chron. 72(6): 591-594.

ARPFA (Alberta Registered Professional Foresters' Association) 1996. Proposal for licensed forestry practice in Alberta. For. Chron. 72(6): 582 .

Bengston, D.N. 1994. Changing forest values and ecosystem management. Society and Natural Resources 7:515-533.

Berg, S. and R. Olszewski. 1995. Forest certification and labeling: a forest industry perspective. Journal of Forestry 93(4): 30-32.

Bombay, H.M. 1996. Sustainable Forest Management includes aboriginal peoples. For. Chron. 72(6): 572.

Cabarle, B., R.J. Hrubes, C. Elliot and T. Synnott. 1995. Certification Accreditation: the need for credible claims. Journal of Forestry 93(4): 13-16.

Christensen, N.L., et al. 1996. The Report of the Ecological Society of America Committee on the Scientific Basis for Ecosystem Management. Ecological Applications 6(3): 665-691.

FORESTCARE. 1996. Annual Report (1996). Alberta Forest Products Association, Edmonton, Alberta.

FORESTCARE. 1997a. Codes of Practice. Alberta Forest Products Association, Edmonton, Alberta.

FORESTCARE. 1997b. Auditor Training Manual. Alberta Forest Products Association, Edmonton, Alberta.

Galindo-Leal, C. and F.L. Bunnell. 1995. Ecosystem Management: Implications and opportunities of a new paradigm. For. Chron. 71(5): 601-606.

Gilmore, D.W. 1997. Ecosystem Management - a needs driven, resource-use philosophy. For. Chron. 73(5): 560-564.

Grumbine, R.E. 1994. What is ecosystem management? Conservation Biology 8: 27-38.

Hughes, R. 1996. Certification of sustainable forest management systems: the importance of field verification. For. Chron. 72(6): 595-597.

Kessler, W.B. 1998. What in the world is sustainable forest management? Fifteenth Annual C.E. Farnsworth Memorial Lecture. State University of New York, College of Environmental Science and Forestry, Syracuse, New York.

Kessler, W.B, H. Salwasser, C.W. Cartwright Jr. and J.A. Caplan. 1992. New perspectives for sustainable natural resource management. Ecological Applications 2(3): 221-225.

Kiekens, J-P. 1998. International registration of forests: an option for FMU-related international cooperation. For. Chron. 74(2): 231-235.

Knight, R.L. and S.F. Bates (eds.) 1995. A new century for natural resources management. Island Press, Washington, DC.

Lapointe, G. 1998. Sustainable forest management certification: The Canadian programme. For. Chron. 74(2): 227-230.

Lee, K.N. 1993. Compass and gyroscope. Island Press, Washington, DC.

Mangel, M. et al. 1996. Principles for the conservation of wild living resources. Ecological Applications 6: 338-362.

Mater, J. 1995. Forest certified products: building tomorrow's products today. Journal of Forestry 93(4): 36-37.

More, T.A. 1996. Forestry's fuzzy concepts: an examination of ecosystem management. Journal of Forestry 94(8):

Rowe, S.J. 1994. A new paradigm for forestry. For. Chron. 70(5): 565-568.

SAF (Society of American Foresters) Study Group. 1995. Forest certification. Journal of Forestry 93(4): 6-10.

Spence, J.R., W.J.A. Volney, V.J. Lieffers, M.G. Weber, S.A. Luchkow and T.W. Vinge. 1999. The Alberta EMEND project: recipe and cook's argument. In T.S. Veeman et al. (eds.). Science and practice: sustaining the boreal forest. pp. 583-590. Sustainable Forest Man- 
agement Network, University of Alberta, Edmonton, Alberta.

Taylor, B., L. Kremsater and R. Ellis. 1997. Adaptive management

of forests in British Columbia. British Columbia Ministry of Forests,

Forest Practices Branch, Victoria, British Columbia.
World Commission on Environment and Development. 1987. Our Common Future. Oxford University Press, New York. 